\section{Association between behaviour at age 3 years and adult criminality ${ }^{\dagger}$}

\author{
JIM STEVENSON and ROBERT GOODMAN
}

\author{
Background The continuity in \\ antisocial behaviour into adulthood from \\ middle childhood is well established but it \\ is not clear whether this is also true of the \\ pre-school period.
}

\begin{abstract}
Aims To determine whether preschool behaviour problems increase the risk of later criminal convictions and add to risk associated with family and social circumstances.
\end{abstract}

\begin{abstract}
Method The records of adult convictions were traced for a general population sample $(n=828)$ initially assessed at age 3 years.
\end{abstract}

Results The risk of having any adult conviction was related to soiling, daytime enuresis, activity level and management difficulties, and that of having an adult violent offence to recent-onset daytime enuresis, management difficulties and temper tantrums. The only other predictors of later convictions were the child's gender and social competence at age 3 years.

Conclusions The presence of specific behaviour problems in the pre-school period places the child at increased risk of being convicted of an adult offence. Family and social circumstances at age 3 years did not predict later convictions.

Declaration of interest None.

†See editorial, pp. 189-190, this issue.
The association between childhood behaviour problems and later criminality has been studied in a number of longitudinal studies. Robbins (1978) has reviewed the early studies. More recently, Bartusch et al (1997) found that from age 5 years childhood antisocial behaviour was significantly associated with convictions for violence at age 18 years, while adolescent antisocial behaviour was more strongly associated with convictions for non-violent offences. Tremblay et al (1994) have shown that impulsivity in the kindergarten period carries the highest risk of later stable delinquent behaviour.

There are few previously published prospective findings on the relationships between early behavioural development before the age of 5 years and adult criminality. Caspi (2000) has presented data on the link between early temperament (but not specific behaviour problems) and adult criminal offences. However, most previous work has been on children first assessed at older ages, either from the general population or from clinic referrals, for example in the classic studies by Farrington (1995) and by Robbins (1966). The study reported here traced the records of adult criminal convictions for a general population sample that had previously been investigated up to the age of 8 years (Richman et al, 1982) to examine whether behaviour problems evident in the pre-school period could predict which individuals would go on to commit criminal offences.

\section{METHOD}

\section{Participants}

The sample was originally identified to take part in a longitudinal epidemiological study of behaviour problems in pre-school children (Richman et al, 1982). It comprised a one-in-four random sample of the cohort of children born in 19691970 who were living in the London borough of Waltham Forest. Of the original 955 children, the parents of 127 were untraceable or refused to take part. The families of a sample of 828 children were contacted and interviewed about the children's behaviour and development at age 3 years, and additional data on the demographic characteristics of the family were obtained. The data at age 3 years were analysed using the full sample of 828 boys and girls.

\section{Measures}

A number of variables were available and principal component analysis was used to provide summary indicators (for more detail on the measures see Richman et al, 1982). To ease interpretation of the results, the measures at age 3 years were constructed so that a high score was likely to be associated with a low risk of an offence. The items scored are listed in the Appendix.

\section{Convictions}

Following ethical committee approval, the Criminal Records Office (CRO) traced both juvenile and adult convictions based upon the child's full name, date of birth and last known address. The tracing was made in 1993 when the participants were aged 23-24 years. Convictions were subdivided into those committed as a juvenile (i.e. before the offenders' 17th birthday) and those committed as an adult. Summary offences (largely non-serious motoring offences) were excluded. Where a particular set of court proceedings involved more than one offence the principal offence was recorded, defined as the one for which the heaviest sentence was imposed, or for which the statutory sentence available to the court was the most severe. The juvenile offences included cautions, and it is possible that some records may have been deleted before the tracing was carried out. Results related to juvenile offences are not presented.

The adult offences represent as full a documentation of criminal activity as can be achieved using tracing based upon the limited identification information that was available. The offences were classified into violent and non-violent offences, based upon the CRO information on the offence. Violent offences included serious wounding, other wounding, robbery, attempted robbery and sexual offences. A conservative approach was taken and a violent offence 
was recorded only when the CRO details specifically mentioned an aggressive or violent component to the offence.

\section{RESULTS}

The number of participants identified as being convicted of committing adult offences in the 828 general population sample was 81 (9.8\%). The majority of those in this group (60) had just one or two offences $(7.2 \%)$ with $21(2.6 \%)$ committing more than this number (up to a maximum of nine offences). The number of violent adult offences was 38 and these were committed by 26 individuals (maximum four offences). The vast majority of the sample $(96.6 \%)$ did not have a juvenile conviction, and the few (28) with juvenile convictions suggests that the tracing of these offences was very incomplete. For this reason the relationship between early factors and later juvenile crime is not analysed.

A salient feature of the adult offences was that most were committed by males $-18.3 \%$ of men and $2.3 \%$ of women had an adult conviction $\left(\chi^{2}=57.25\right.$, d.f. $=1$, $P<0.001)$; odds ratio $9.50,95 \%$ confidence interval 4.83-18.72. This effect was even more marked for adult violent convictions: $6.5 \%$ of men and $0.2 \%$ of women $\left(\chi^{2}=23.84, \quad\right.$ d.f. $=1, \quad P<0.001$; $\mathrm{OR}=29.83$, 95\% CI 4.02-221.25).

\section{Behaviour at age 3 years and adult criminality}

The relationship between behaviour at age 3 years and adult criminality was examined with individual items of problem behaviour recoded as either markedly present or absent, and cross-tabulated against the presence or absence of adult convictions, both in total and for violent offences alone. The results are presented in Table 1, where minor variations in $n$ result from missing data. A $\chi^{2}$ test was used to establish the significance of the relationship between behaviour problems and being convicted of an offence.

A number of individual behaviours were significantly related to an increased risk of an adult conviction: soiling $(\mathrm{OR}=2.32,95 \% \mathrm{CI}$ 1.30-4.81), daytime enuresis $(\mathrm{OR}=2.21$, $95 \%$ CI $1.31-3.72)$, activity $(\mathrm{OR}=2.42$, 95\% CI 1.40-4.21) and management difficulties $(\mathrm{OR}=2.71,95 \%$ CI $1.50-4.89)$. Two behaviours were significantly related to adult violent offences - recent-onset

Table I Relationship between presence of marked behaviour problems at age 3 years and adult convictions

\begin{tabular}{|c|c|c|c|c|c|c|c|c|}
\hline \multirow[t]{3}{*}{ Behaviour problem } & \multicolumn{4}{|c|}{ Percentage with marked behaviour problems } & \multicolumn{4}{|c|}{ Percentage with marked behaviour problems } \\
\hline & \multicolumn{2}{|c|}{ All adult convictions } & \multirow[t]{2}{*}{$\chi^{2}$} & \multirow[t]{2}{*}{$P$} & \multicolumn{2}{|c|}{ Adult violent convictions } & \multirow[t]{2}{*}{$\chi^{2}$} & \multirow[t]{2}{*}{$P$} \\
\hline & $\begin{array}{c}\text { None } \\
n=730-743\end{array}$ & $\begin{array}{c}\text { Conviction } \\
n=79-81\end{array}$ & & & $\begin{array}{c}\text { None } \\
n=783-798\end{array}$ & $\begin{array}{c}\text { Conviction } \\
n=25-26\end{array}$ & & \\
\hline Soiling & 10.4 & 21.3 & 7.36 & $<0.008$ & II.I & 23.1 & 2.49 & NS \\
\hline \multicolumn{9}{|l|}{ Enuresis } \\
\hline daytime & 15.2 & 28.4 & 8.25 & $<0.005$ & 16.1 & 30.8 & 2.96 & NS \\
\hline night-time & 45.6 & 51.9 & 0.93 & NS & 46.5 & 34.6 & 1.00 & NS \\
\hline Recent-onset soiling & 1.8 & 3.8 & 0.64 & NS & 1.9 & 3.8 & 0.00 & NS \\
\hline \multicolumn{9}{|l|}{ Recent-onset enuresis } \\
\hline daytime & 2.0 & 4.9 & 1.61 & NS & 2.0 & 11.5 & 6.36 & $<0.01$ \\
\hline night-time & 4.4 & 4.9 & 0.00 & NS & 4.4 & 7.7 & 0.10 & NS \\
\hline Pica & 7.1 & 3.8 & 0.78 & NS & 6.9 & 3.8 & 0.05 & NS \\
\hline Poor appetite & 15.6 & 21.0 & 1.19 & NS & 15.8 & 26.9 & 1.56 & NS \\
\hline Food fads & 13.3 & 8.6 & $\mathrm{I} .04$ & NS & 12.7 & 19.2 & 0.47 & NS \\
\hline Worries & 2.5 & 0.0 & 1.03 & NS & 2.3 & 0.0 & 0.10 & NS \\
\hline A number of fears & 10.6 & 10.0 & 0.00 & NS & 10.8 & 3.2 & 0.65 & NS \\
\hline Mood & 3.5 & 2.5 & 0.02 & NS & 3.4 & 3.8 & 0.00 & NS \\
\hline Relations with others & 5.4 & 6.3 & 0.00 & NS & 5.3 & II.5 & 0.88 & NS \\
\hline Relations with siblings & 8.5 & $\mathrm{II} .4$ & 0.41 & NS & 8.5 & 20.0 & 2.71 & NS \\
\hline Dependency & 5.3 & 10.0 & 2.18 & NS & 5.7 & 7.7 & 0.00 & NS \\
\hline Seeks attention & 9.0 & 10.3 & 0.03 & NS & 9.3 & 3.8 & 0.37 & NS \\
\hline Concentration & 6.3 & 10.1 & 1.16 & NS & 6.3 & 15.4 & 2.03 & NS \\
\hline Activity & 12.1 & 25.0 & 9.30 & $<0.003$ & 12.9 & 26.9 & 3.14 & NS \\
\hline In parents' bed & II.I & 13.6 & 0.22 & NS & 11.3 & 15.4 & 0.12 & NS \\
\hline Going to bed & 12.4 & 18.5 & 1.18 & NS & 12.7 & 23.1 & 1.56 & NS \\
\hline Night waking & 13.6 & 13.6 & 0.00 & NS & 13.7 & 11.5 & 0.00 & NS \\
\hline Management difficulties & 9.1 & 21.3 & 10.36 & $<0.002$ & 9.8 & 23.1 & 3.46 & $(0.06)$ \\
\hline Tantrums & 4.9 & 7.4 & 0.51 & NS & 4.8 & 15.4 & 3.83 & $<0.05$ \\
\hline A number of habits & 15.3 & 13.6 & 0.06 & NS & 15.2 & II.5 & 0.06 & NS \\
\hline
\end{tabular}


daytime enuresis $(\mathrm{OR}=6.37$, 95\% CI 1.73 23.38) and tantrums $(\mathrm{OR}=3.61,95 \% \mathrm{CI}$ 1.19-11.01) - with management difficulties just failing to reach significance $(P<0.06)$ $(\mathrm{OR}=2.75,95 \%$ CI $1.07-7.05)$.

To establish how well the scores on behaviours at age 3 years could predict adult crime, two discriminant function analyses were conducted with 'all adult convictions' and 'adult violent convictions' as the dependent variables. The accuracy of classification was calculated using the 'leave one out' procedure (Everitt, 1996). The 24 behaviour items predicted the presence of an adult conviction with a sensitivity of $34 \%$ and specificity of $73 \%$. The corresponding values for adult violent crime were $24 \%$ and $80 \%$ respectively.

\section{Child and social characteristics at age 3 years and later criminality}

There were 11 variables measuring aspects of the child and the child's social circumstances at age 3 years, including an aggregated measure of behaviour problems. Of these, three (gender, social development and the total behaviour score) were found to be significant predictors of being convicted of any adult offence using logistic regression (Table 2).

The relationship between behaviour at age 3 years and adult criminality remains significant when gender and social development are added to the logistic regression. Interviewer rating of behaviour scores produces a significant improvement in fit when added after gender and social development $\left(\chi^{2}\right.$ change $=5.05$, d.f. $=1$, $P<0.03$; OR $=0.95,95 \%$ CI $0.91-0.99$ ).

The same three factors were significantly related to the conviction for an adult violence offence (Table 2). However, for this analysis the effects of interviewer ratings of behaviour are no longer significant when gender and social development are entered first into the logistic regression $\left(\chi^{2}\right.$ change $=1.01$, d.f. $=1, \mathrm{NS} ; \mathrm{OR}=0.96$, 95\% CI 0.90-1.03).

The discriminant function analyses were repeated, adding as predictors 10 of these child and social characteristics (i.e. without the aggregate behaviour score) to the 24 individual items of difficult behaviour. The sensitivity for all adult convictions was $69 \%$ and the specificity was $69 \%$. For adult violent convictions the combined behaviour, child and social characteristics were able to predict with a sensitivity of $50 \%$ and a specificity of $80 \%$. These child and family characteristics in concert do improve the accuracy of prediction (particularly the sensitivity), although individually each variable has only a weak relationship with adult outcome.

\section{Individual behaviour problems and later offences, controlling for gender and social development}

The association between gender, social development and adult convictions demonstrated above raises the possibility that the links between specific behaviours and adult convictions might arise through their association with these two factors and might not represent a specific association at all. Accordingly, a series of logistic regressions were conducted with gender and social development entered first as predictors and the individual behaviours entered separately at a second step.

With all adult offences as the dependent variable, the associations with soiling $\left(\chi^{2}\right.$ change $=3.00$, d.f. $=1$, NS; OR $=1.23,95 \%$ CI $0.98-1.54)$ and daytime enuresis $\left(\chi^{2}\right.$ change $=3.02$, d.f. $=1, \mathrm{NS} ; \mathrm{OR}=1.50,95 \%$ CI 0.97-2.32) were no longer significant. However, for activity $\left(\chi^{2}\right.$ change $=6.75$, d.f. $=1, P<0.01 ; \mathrm{OR}=1.86,95 \%$ CI 1.17 2.96) and management difficulties $\left(\chi^{2}\right.$ change $=12.92$, d.f. $=1, P<0.001 ; \mathrm{OR}=1.91$, 95\% CI 1.34-2.72) the associations remained significant.

With adult violent offences as the dependent variable, both recent-onset daytime enuresis $\left(\chi^{2}\right.$ change $=1.01$, d.f. $=1$; $\mathrm{OR}=1.43,95 \%$ CI $0.73-2.81)$ and management difficulties $\left(\chi^{2} \quad\right.$ change $=0.63$, d.f. $=1 ; \mathrm{OR}=1.26,95 \%$ CI $0.71-2.24)$ were no longer significant. Temper tantrums did continue to show a significant association with adult violent offences $\left(\chi^{2}\right.$ change $=8.72$, d.f. $=1, P<0.01 ; O R=2.70,95 \%$ CI 1.34-5.25). Previous analysis of temper tantrums in this sample had shown that they were associated with a range of dysfunctional features of the family including marital stress and social disadvantage (Needlman et al, 1991). Accordingly, the logistic regression was run again with all the variables in Table 2 (except the aggregate behaviour score) entered first and then

Table 2 Logistic regression analysis predicting any adult convictions and adult violent convictions from child and family characteristics at age 3 years $(n=828$ )

\begin{tabular}{|c|c|c|c|c|c|c|c|c|}
\hline & \multicolumn{4}{|c|}{$\begin{array}{l}\text { Any adult convictions } \\
\text { Univariate logistic regression d.f. }=I\end{array}$} & \multicolumn{4}{|c|}{$\begin{array}{l}\text { Adult violent convictions } \\
\text { Univariate logistic regression d.f. }=I\end{array}$} \\
\hline & $\chi^{2}$ & $P$ & OR & $95 \% \mathrm{Cl}$ & $\chi^{2}$ & $P$ & OR & $95 \% \mathrm{Cl}$ \\
\hline Gender & 63.53 & $<0.001$ & 0.11 & $0.05-0.21$ & 39.55 & $<0.001$ & 0.00 & $0.00-0.00$ \\
\hline Immigrant status & 0.44 & NS & 0.80 & $0.40-1.60$ & 1.25 & NS & 0.47 & $0.11-2.03$ \\
\hline Social class & 2.48 & NS & 1.55 & $0.88-2.73$ & 1.53 & NS & 1.81 & $0.67-4.80$ \\
\hline Family size & 2.61 & NS & 1.17 & $0.97-|.4|$ & 3.36 & NS & 1.33 & $0.99-1.77$ \\
\hline Family status & 0.68 & NS & $\mathrm{I} .44$ & $0.63-3.30$ & 0.34 & NS & 0.58 & $0.08-4.33$ \\
\hline Family stress & 0.35 & NS & 1.05 & $0.90-1.22$ & 0.69 & NS & 1.12 & $0.85-1.49$ \\
\hline Social disadvantage & 1.32 & NS & 0.88 & $0.72-1.08$ & 0.36 & NS & 1.14 & $0.72-1.82$ \\
\hline Language development & 2.80 & NS & 0.87 & $0.72-1.08$ & 2.82 & NS & 0.74 & $0.53-1.03$ \\
\hline Physical development & 2.04 & NS & 0.87 & $0.72-1.05$ & 2.75 & NS & 0.77 & $0.57-1.04$ \\
\hline Social development & 5.93 & $<0.02$ & 0.88 & $0.80-0.97$ & 6.58 & $<0.02$ & 0.82 & $0.7 \mathrm{I}-0.95$ \\
\hline Total behaviour score & 10.57 & $<0.001$ & 0.94 & $0.90-0.98$ & 4.63 & $<0.05$ & 0.93 & $0.88-0.99$ \\
\hline
\end{tabular}


temper tantrums entered as a second step. With adult violent crime as the dependent variable, temper tantrums still contributed significantly to the prediction even when all these additional indicators were taken into account $\left(\chi^{2}\right.$ change $=8.43$, d.f. $=1$, $P<0.005 ; \mathrm{OR}=2.91,95 \%$ CI $1.38-6.09)$.

\section{DISCUSSION}

This longitudinal study has provided evidence that there are continuities in behaviour that produce an association between behaviour in the pre-school period (specifically at age 3 years) and later adult crime. Externalising behaviours such as temper tantrums and management difficulties (e.g. non-compliance) were associated with adult convictions, in particular with violent offences. A second group of behaviours were also associated with later convictions and these included soiling and enuresis. The relationship with bowel and bladder control disappeared when gender and social development were controlled for. It would appear then that these sphincter control difficulties are only associated with later adult crime because they are more common in boys than in girls and reflect a more general retardation (Biederman et al, 1995) rather than specific behavioural risk factors.

Importantly, it was the externalising behaviours that showed a specific association with adult convictions, and the homotypic links between temper tantrums, activity level and management difficulties in contrast do seem to represent early manifestations of a continuing behavioural style that lasts into adulthood. There have been previous reports linking early temper tantrums with later criminality but these have been based on retrospective data (Sampson \& Laub, 1993). Prospective studies have shown an association between temper tantrums at age $8-10$ years and a range of difficulties in adult life in both genders, including downward social mobility and divorce (Caspi et al, 1987). Although temper tantrums in this sample were associated with a number of adverse circumstances including maternal depression, family stress and social disadvantage (Needlman et al, 1991), the association between temper tantrums at age 3 years and adult violent crime is maintained when these other factors are controlled for.

\section{Significance of elevated activity levels}

Activity level was one of the behaviours that were predictive of adult crime. Stevenson (1996) has reviewed the association between hyperactivity and conduct disorder. There is well-replicated evidence that for some children conduct disorder is a secondary consequence of hyperactivity. Specific associations have been found between hyperactivity-impulsivity (but not inattention) measured at age 9 years and later officially recorded arrests and selfreported crime for males (Babinksi et al, 1999). The findings reported here replicate these specific associations and extend them to behaviours measured at age 3 years, since activity but not poor concentration (i.e. inattention) was related to adult crime.

There is substantial evidence that hyperactivity is one of the most strongly genetically influenced facets of early developing behaviour (Goodman \& Stevenson, 1989; Rutter et al, 1999). This is just one mechanism whereby genetic influence on conduct disorder and Moffitt's (1993) 'life-course-persistent antisocial behaviour' arises (Bock \& Goode, 1996). However, as formulated by Lahey et al (1999), the concept of an enduring antisocial propensity reflects a broader range of temperamental or dispositional influences than just hyperactivity. In the present study temper tantrums and management difficulties, reflecting deficits in emotional selfregulation and oppositional temperament, were also related to later criminality. These findings provide support for the proposal from Lahey et al (1999) that the pathways to the development of antisocial behaviour are influenced by a constellation of earlydeveloping temperamental features which in turn may affect later behaviour directly through the continuing action of genetic factors or indirectly through gene-environment interaction.

\section{Temperamental differences}

Data from the Dunedin study have been used to investigate the relationship between behaviour in the pre-school period and later development. Caspi (2000) has presented findings of the relationship between temperamental qualities in 1037 children measured at age 3 years and criminality measured at 21 years. The overall rates of criminal convictions were slightly higher in this New Zealand sample (14\% compared with $10 \%$ in the present study). There was a degree of homotypic continuity in that children with poorly controlled temperaments at 3 years of age had higher rates of self-reported criminal offences and higher recidivism rates in official records. Although not based on measured behaviour problems per se, the findings from Caspi (2000) support the link between externalising behaviour problems and adult criminality found in the present study.

As well as the behaviours showing associations with later criminality, it is important to consider the behaviours that did not show evidence of increased risk. In the Dunedin study children who were temperamentally inhibited had rates of criminality no different from children who were well adjusted at age 3 years (Caspi, 2000). In the present study, for all adult offences there was no indication that problems with food, mood, worries or fears were associated. Neither were relations with other children inside or outside the family. Finally, none of the problems related to sleep indicated a risk. There was no a priori reason to expect these largely non-externalising problems to be associated with later criminality, and the absence of an association gives confidence that behaviours that did show an association were not just chance findings arising from multiple tests of significance. The small number committing adult violent offences makes it more difficult to identify significant associations. Again, food-related behaviours, sleep problems, and worries and fears were not associated with elevated rates of convictions for violent offences. However, a number of problems did show indications of elevated risk (although not significant). These include soiling and daytime wetting, poor sibling relationships and poor concentration.

\section{Family risk factors}

One feature of the results is that the only measures on this sample that predicted adult criminality were characteristics of the children themselves - behaviour, gender and social development at 3 years of age. Broader measures of immigrant status, early family stresses, family status, family size, social disadvantage and social class were not individually predictive of adult convictions. Other studies have shown that specific aspects of family relationships, parents' mental state and, in particular, parental criminality do contribute to later criminality (Farrington, 
1995). Data on these features of the family setting were not available for the total sample of children entering into the analyses presented here.

\section{Implications for planning services}

The implications for practice need to be treated with caution. In particular, the accuracy of predicting adult crime from characteristics of the child or the family in the pre-school period needs to be carefully appraised. The best prediction obtained had a sensitivity and a specificity of $69 \%$. Expressing this result another way, the positive predictive value (PPV, i.e. the proportion of cases predicted to be at risk that actually commit an offence) is $19 \%$. The PPV is low because the prevalence rate of adult criminality is low and the specificity is low too. Bennett et al (1998) reviewed the predictive accuracy of conduct obtained in longitudinal studies and found an average specificity ( $85 \%$ ) somewhat higher than that obtained here. Clearly, a substantial number of cases at risk will be falsely labelled, and only just over half the cases having a later criminal conviction would be identified. Any service hoping to develop preventive strategies based on early characteristics needs to take into account the costs to these children and their families of being erroneously identified as at risk of committing violent offences in later life.

The treatment and the prevention of conduct disorder and antisocial behaviour have been discussed by Reid (1993). He concluded that family-based interventions were appropriate during the pre-school years but that subsequently these need to be supplemented by work in a variety of settings. The results presented here support the potential value of early intervention and treatment in attempts to prevent the child entering the cycle of disruptive behaviour and consequent adverse experiences that produce persistent antisocial behaviour. However, it is essential that the difficulties, which Bennett et al (1998) have carefully laid out, be considered before preventive intervention for targeted individuals be put in place. These include the false labelling of risk (especially for girls), the need for multiple-stage assessments rather than single time-point screens, and the potential value of including measures of neuropsychological functioning and family risk factors.

\section{CLINICAL IMPLICATIONS}

Children displaying externalising behaviour problems such as temper tantrums, high activity levels and management difficulties at age 3 years have a long-term risk of criminality in adulthood.

- The accuracy of long-term prediction of adult criminality (positive predictive value) from the behavioural profile alone is insufficient to justify the targeting of services at specific individuals.

- Multiple-stage assessments that include family risk and neuropsychological functioning are needed to assess the likelihood of continuation of the antisocial behaviour of pre-school children who show externalising behaviour problems.

\section{LIMITATIONS}

- The study does not include data on changes in family circumstance, life events or information on subsequent aspects of the children's development that could identify factors moderating the risk of adverse long-term outcome.

- The data obtained on convictions during adolescence were too sparse to permit testing for differential continuities in antisocial behaviour from early childhood to adolescence and adulthood.

- Although adult criminal convictions represent a valuable outcome measure that avoids biases arising from using the same sources of information on behaviour in childhood and adulthood, there will be aspects of antisocial behaviour in adulthood that will not have been identified through this means.

JIM STEVENSON, PhD, Centre for Research into Psychological Development, Department of Psychology, University of Southampton; ROBERT GOODMAN, FRCPsych, Department of Child and Adolescent Psychiatry, Institute of Psychiatry, King's College, London, UK

Correspondence: Professor Jim Stevenson, Centre for Research into Psychological Development, Department of Psychology, University of Southampton, Highfield, Southampton SOI7 IBJ, UK. Tel: +44 (0)I703 592 583; fax: +44 (0)I703 594 719; e-mail: jsteven@psy.soton.ac.uk

(First received 26 January 2000, final revision 25 October 2000, accepted 25 October 2000)

The results of the present study are of interest for two reasons. They provide independent long-term validation of the significance of early emerging behaviour problems - a perspective from child psychiatry. These problems, even when based on parental report, are predictive of some aspects of adult dysfunctional behaviour identified by an independent source. They are also of interest from the perspective of adult forensic psychiatry. There is clearly some scope for extending prevention programmes into the pre-school period. Behaviours predictive of later criminality do not emerge only when the child enters school, but are identifiable before that stage.

\section{ACKNOWLEDGEMENTS}

The data on the early development of the children were obtained from the Waltham Forest Longitudinal Study by a team coordinated by Naomi Richman, Philip Graham and Jim Stevenson at the Institute of Child Health, University College London. The data on of fences were obtained with the cooperation of the Criminal Records Office and we are grateful to Joe Black and David Farrington for advice on the coding of offence data. Richard Martin provided assistance with the initial stages of data analysis.

\section{APPENDIX}

Variables scored at age 3 years

Gender

Male, I; female, 2. 


\section{Immigrant status}

Mother born outside country or mother's mother not resident for more than 10 years at time of birth: no, I; yes, 2

\section{Social class}

Social class based on the Registrar General's classification of occupations - 1970: I, 7; II, 6; II non-manual, 5; IV non-manual, 4; III manual, 3; IV manual, $2 ; \mathrm{V}, \mathrm{I}$.

\section{Family size}

Number (reversed) of children in the family under the age of 16 years.

\section{Family status}

Living with both natural parents, 2; all others, I.

\section{Family stress}

Count (reversed) of the number of stressful life events in the year preceding the child's third birthday.

\section{Social disadvantage}

An index of poverty based upon the first principal component for measures of housing quality, amenities and overcrowding.

\section{Language development}

Score on the first principal component for three tests of expressive vocabulary, syntax and comprehension.

\section{Physical development}

Mother's report of fine and gross motor development.

\section{Social development}

Score of social competencies based on items from the Vineland Social Maturity Scale (Dou, 1965)

\section{Behaviour}

Interviewer ratings were made of the severity of 24 individual items of behaviour from the Behaviour Screening Questionnaire (Richman \& Graham, 1971); scores of 0, no problem or mild problem or I, marked problem were assessed for the following items: soiling, day wet, night wet, recent-onset soiling, recent-onset day wet, recent-onset night wet, pica, poor appetite, food fads, worries, number of fears, mood, relationship with other children, relationship with siblings, dependency, seeking attention, concentration, activity, in parents' bed, going to bed, night waking, management difficulties, tantrums, number of habits.

In addition an aggregated 'total behaviour' score was derived from the following 12 aspects of behaviour, each scored 2, no problem, I, mild problem or 0, marked problem (see Richman \& Graham, 1971 for full details of aggregate scoring and the validation of the scale): eating, sleeping, soiling, worries, fears, mood, relationships with other children, dependency, seeking attention, concentration, activity, management difficulties and tantrums.

\section{REFERENCES}

Babinski, L. M., Hartsough, C. S. \& Lambert, N. M. (1999) Childhood conduct problems, hyperactivityimpulsivity, and inattention as predictors of adult criminal activity. Journal of Child Psychology and Psychiatry, 40 347-355.

Bartusch, D. R. J., Lynam, D. R., Moffitt, T. E., et al (1997) Is age important? Testing a general versus a developmental theory of antisocial behavior. Criminology, 35, 13-48.

Bennett, K. J., Lipman, E. L., Racine, Y., et al (1998) Annotation: do measures of externalising behaviour in normal populations predict later outcome? Implications for targeted interventions to prevent conduct disorder. Journal of Child Psychology and Psychiatry, 39, 1059-1070.

Biederman, J., Santangelo, S. L., Faraone, S. V., et a (1995) Clinical correlates of enuresis in ADHD and nonADHD children. Journal of Child Psychology and Psychiatry, 36, 865-877.

Bock, G. R. \& Goode, J. A. (1996) Genetics of Criminal and Antisocial Behaviour. CIBA Foundation Symposium 194. Chichester: John Wiley \& Sons.

Caspi, A. (2000) The child is father of the man: personality continuities from childhood to adulthood. Journal of Personality and Social Psychology, 78, 158-172.

_ , Edler, G. H. \& Bern, D. J. (1987) Moving against the world: life-course patterns of explosive children. Developmental Psychology, 23, 308-313.

Dou, E. A. (1965) Vineland Social Maturity Scale. Circle Pines, MN: American Guidance Service.

Everitt, B. S. (1996) Making Sense of Statistics in Psychology. Oxford: Oxford University Press.

Farrington, D. P. (1995) The Twelfth Jack Tizard Memorial Lecture. The development of offending and antisocial behaviour from childhood: key findings from the Cambridge Study in Delinquent Development. Journal of Child Psychology and Psychiatry, 36, 929-964.

Goodman, R. \& Stevenson, J. (1989) A twin study of hyperactivity -2 . The aetiological role of genes, family relationships and perinatal adversity. Journal of Child Psychology and Psychiatry, 30, 691-709.

Lahey, B. B., Waldman, I. D. \& McBurnett, K. (1999) Annotation: the development of antisocial behavior: an integrative causal model. Journal of Child Psychology and Psychiatry, 40, 669-682.

Moffitt, T. E. (1993) Adolescence-limited and lifecourse-persistent antisocial behavior - a developmental taxonomy. Psychological Review, 100, 674-70l.

Needlman, R., Stevenson, J. \& Zuckerman, B. (1991) Psychosocial correlates of severe temper tantrums. Journal of Developmental and Behavioral Pediatrics, 12 77-83.

Reid, J. B. (1993) Prevention of conduct disorder before and after school entry - relating interventions to developmental findings. Development and Psychopathology, 5, 243-262.

Richman, N. \& Graham, P. (1971) A behaviour screening questionnaire for use with three year old children. Journal of Child Psychology and Psychiatry, 12 5-33.

_, Stevenson, J. \& Graham, P. (1982) Preschool to School: A Behavioural Study. London: Academic Press.

Robbins, L. N. (1966) Deviant Children Grown Up. Baltimore: Williams \& Wilkins.

- (1978) Sturdy childhood predictors of adult antisocial behavior: replications from longitudinal studies. Psychological Medicine, 8, 611-622.

Rutter, M., Silberg, J., O'Connor, T., et al (1999)

Genetics and child psychiatry: ii - empirical research findings. Journal of Child Psychology and Psychiatry, 40, 19-55.

Sampson, R. J. \& Laub, J. H. (1993) Crime in the Making: Pathways and Turning Points Through Life. Cambridge, MA: Harvard University Press.

Stevenson, J. (1996) The hyperactive child at school. In Hyperactivity Disorders (ed. S. Sandberg). Cambridge: Cambridge University Press.

Tremblay, R. E., Pihl, R. O., Vitaro, F., et al (1994) Predicting early-onset of male antisocial-behavior from preschool behavior. Archives of General Psychiatry, 5I, 732-739. 